\title{
The evaluation of an FFQ to determine energy, macronutrient, calcium, iron and zinc intakes of infants aged 12 months
}

\author{
L. D. Marriott ${ }^{1}$, H. M. Inskip ${ }^{1}$, S. E. Borland ${ }^{1}$, C. Cooper ${ }^{1}$, K. M. Godfrey ${ }^{1}$, C. M. Law ${ }^{2}$ \\ and S. M. Robinson ${ }^{1}$ \\ ${ }^{1}$ MRC Epidemiology Resource Centre, Southampton, UK and ${ }^{2}$ Centre for Paediatric Epidemiology and Biostatistics, \\ Institute of Child Health, London, UK
}

The aim was to compare the energy and nutrient intakes from an FFQ, devised to assess the diets of infants aged 12 months with those from a $4 \mathrm{~d}$ weighed-diet diary (WD) completed for the same fifty infants.

Infants in the Southampton Women's Survey ${ }^{(1)}$ are visited within the period 2 weeks before and 3 weeks after their first birthdays. The frequency of consumption and amount consumed for milks and seventy-eight food items during the 4 weeks preceding the interview are recorded. A subsample of families completed a WD, in which all milks and foods consumed by the infant were recorded. Breast-milk intake was estimated using an algorithm ${ }^{(2)}$. The median intakes and interquartile ranges (IQR) for energy, macronutrients, Ca, Fe and $\mathrm{Zn}$ are reported, together with Spearman rank correlation coefficients $(r)$ in the Table.

In the sub-sample of infants assessed by FFQ and WD $46 \%$ were girls. The FFQ produced higher median values for energy and all nutrients compared with the WD but the values for $r$ indicated reasonable agreement in the ranking of infants' intakes between methods. The greatest differences in intakes were for $\mathrm{Fe}$ and $\mathrm{Zn}$, which were partly accounted for by the lower number of infants consuming an infant formula at the time of the WD.

\begin{tabular}{|c|c|c|c|c|c|}
\hline & \multicolumn{2}{|c|}{ FFQ $(n 50)$} & \multicolumn{2}{|c|}{$\mathrm{WD}(n 50)$} & \multirow[b]{2}{*}{$r$} \\
\hline & Median & IQR & Median & IQR & \\
\hline Energy $(\mathrm{kJ})$ & 4422 & $4044-5550$ & 3771 & $3426-4315$ & 0.46 \\
\hline Protein $(\mathrm{g})$ & 37.0 & $32.6-52.1$ & 34.5 & $28.9-39.4$ & 0.52 \\
\hline Fat $(\mathrm{g})$ & 42.4 & $38.3-52.6$ & 36.6 & $33.8-46.3$ & 0.36 \\
\hline Carbohydrate (g) & 135 & $117-155$ & 112 & $96-127$ & 0.49 \\
\hline $\mathrm{Ca}(\mathrm{mg})$ & 877 & $783-978$ & 784 & $611-990$ & 0.65 \\
\hline $\mathrm{Fe}(\mathrm{mg})$ & 8.48 & $5.92-10.72$ & 5.20 & $3.96-7.40$ & 0.44 \\
\hline $\mathrm{Zn}(\mathrm{mg})$ & 6.25 & $5.37-7.40$ & 4.54 & $3.97-5.48$ & 0.39 \\
\hline
\end{tabular}

In population studies the FFQ provides useful information ranking the intakes of infants aged 12 months.

1. Inskip HM, Godfrey KM, Robinson SM, Law CM, Barker DJ \& Cooper C (2006) Int J Epidemiol 35, $42-48$.

2. Mills A \& Tyler H (1992) Food and Nutrient Intakes of British Infants Aged 6-12 Months. Appendix V, p. 117. London: H. M. Stationery Office. 